\title{
Diagnosis of gastric anisakiasis by abdominal ultrasonography
}

Toru Ishikawa*, Yuichi Kojima, Motoi Azumi, Michitaka Imai, Yujiro Nozawa, Akito Iwanaga, Tomoe Sano, Terasu Honma and Toshiaki Yoshida

Department of Gastroenterology and Hepatology, Saiseikai Niigata Hospital, Niigata, Japan

Gastrointestinal anisakiasis is an uncommon zoonotic parasitic infection caused by consumption of raw or undercooked seafood infected with nematodes of genus Anisakis. A 44-year-old woman presented to our emergency department with acute upper abdominal pain $14 \mathrm{~h}$ after ingestion of Mackerel sashimi. During physical examination, she was found to have tenderness in the epigastric region. Abdominal ultrasonography showed markedly and diffusely thickened walls from the pylorus to the gastric corpus, very smooth surfaces and low homogeneous internal echoes (Figure 1a). Emergency gastroscopy identified $12 \mathrm{~mm}$ and $14 \mathrm{~mm}$ long larva of the nematode Anisakis simplex penetrating the inflamed body of the stomach (Figure 1b). Disinfestation rapidly resolved the patient's symptoms. Ultrasonography is useful to diagnosis gastric anisakiasis which shows a thickened wall $[1,2]$.

\section{Sources of support}

There are no conflicts of interest in the manuscript.

\section{Declaration of personal and funding interests}

None.

\section{Financial disclosure}

The authors declare that they do not have any current financial arrangements or affiliations with any organization that may have a direct interest in their work.

\section{References}

1. Lalchandani UR, Weadock WJ, Brady GF, Wasnik AP (2018) Imaging in gastric anisakiasis. Clin Imaging 50: 286-288.

2. Kondo T (2018) Woe sushi: gastric anisakiasis. Lancet 13: 1340.

Copyright: (C2019 Taooka Y. This is an open-access article distributed under the terms of the Creative Commons Attribution License, which permits unrestricted use, distribution, and reproduction in any medium, provided the original author and source are credited.
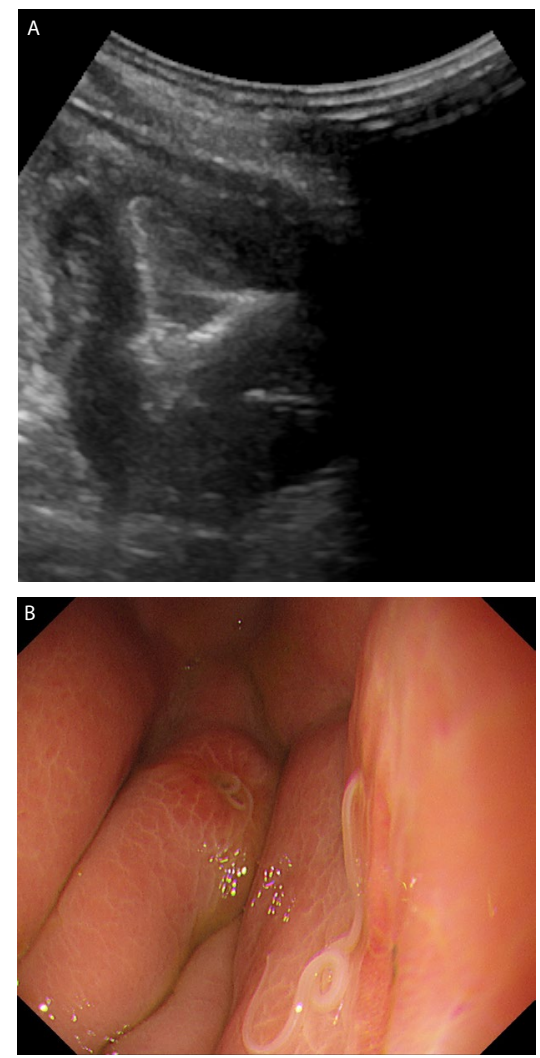

Figure 1. (A) Images of abdominal ultrasonograghy. Markedly edematous wall. (B) Endoscopic image of the patient. An Anisakis larva was seen in the stomach, and the adjacent mucosa was swollen 